\title{
Preservação de documentos para a história do teatro brasileiro: teoria e prática
}

Preservation of documents for the history of the Brazilian theater: theory and practice

\section{Elizabeth Ribeiro Azevedo}

Elizabeth Ribeiro Azevedo

Professora do Departamento de Artes Cênicas e do PPGAC da Escola de Comunicações e Artes da Universidade de São Paulo (USP). Coordenadora do Centro de Documentação Teatral da ECA-USP.

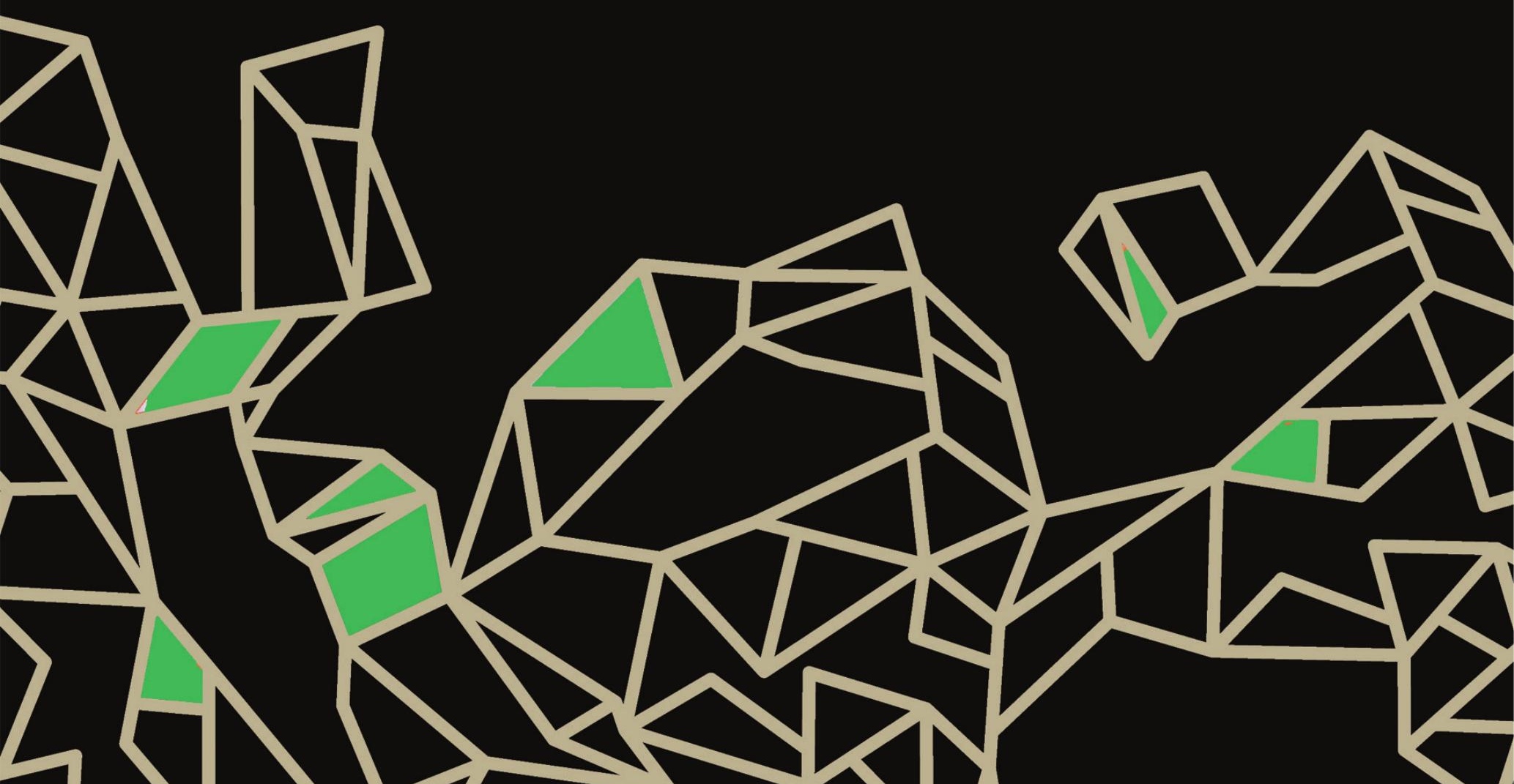




\section{Resumo}

De início, este artigo apresenta rápidas considerações sobre as relações entre documentos e a história do teatro brasileiro. Em seguida, considera as formas pelas quais são constituídos alguns dos acervos nacionais abrigados em instituições públicas e privadas. Finalmente, apresenta justificativas para a criação do Centro de Documentação Teatral na Universidade de São Paulo e algumas das escolhas teórico-metodológicas feitas para o tratamento de seu acervo e das atividades de pesquisa que vem desenvolvendo.

Palavras-chave: Centro de documentação, Teatro brasileiro, Arquivos pessoais, Contextualização.

\section{Abstract}

First of all, this article presents some brief considerations on the relations between documents and history of Brazilian theater. Hereupon it considers the ways in which some of the national collections located in public and private institutions are constituted. Finally, it presents some justifications for the foundation of the Theatrical Documentation Center at University of São Paulo and some theoretical-methodological choices made for the treatment of its collection and the research activities it has been developing.

Keywords: Documentation center, Brazilian theater, Personal papers, Contextualization.

Como outras modalidades da pesquisa histórica, a história do teatro brasileiro, para ser feita com rigor e consequência, depende em grande parte do uso de documentos como fontes de informação. Tal afirmação pode parecer óbvia e simples à primeira vista, mas na verdade não é.

Da extensa relação entre os documentos e a narrativa histórica, que não cabe aqui recompor, vale a pena mencionar o longo tempo em que a documentação escrita, oriunda das atividades oficiais, foi vista como fonte praticamente única, tida como inquestionável, para uma história que se debruçava sobre as questões político-administrativas e elegeu o registo oficial 
escrito como documento "neutro", de onde poderia "emanar" a "verdade" sobre os problemas que os historiadores então se colocavam.

Dada, portanto, a importância fundamental atribuída a essa massa documental, como prova de direito e de interesse científico, surgiram instituições, metodologias, especialistas e uma ciência que se encarregou de organizá-la em Arquivos Nacionais ${ }^{1}$ e outras instituições de guarda que preservariam indefinidamente o material antigo acumulado ao longo dos séculos anteriores, e se ocupariam em estabelecer critérios de recolhimento futuro. A criação de tais instituições e a autoridade para que estabelecessem políticas de preservação se deu por força de leis elaboradas, com maior ou menor abrangência, ao longo dos anos.

Com a ampliação do campo da pesquisa histórica a partir do surgimento de novos assuntos e abordagens que passaram a interessar aos historiadores, muito do que até então era tratado ainda como um tipo de crônica sem rigor científico passou a ser elaborado com metodologia estrita e perspectiva teórica adequada. Portanto, a nova história buscou suas próprias fontes, fazendo emergir uma enormidade de material, que passou a ser encarado como fonte passível de ser utilizada pelos investigadores. Jornais, revistas, obras de arte, objetos do cotidiano, práticas coletivas, relatos orais, entre muitas outras, ganharam status de informativos e provas, fazendo com que uma série de metodologias de utilização e crítica a esses novos documentos fosse desenvolvida. Mesmo a documentação oficial sofreu também uma transformação a partir de novas questões que lhe eram postas.

$\mathrm{Na}$ esteira das novas práticas, a história do teatro brasileiro também sofreu consequências. Os primeiros relatos sobre as atividades teatrais no Brasil, em geral referentes à literatura dramática, apareceram com as primeiras histórias da literatura brasileira ${ }^{2}$, enquanto os panoramas iniciais dedicados exclusivamente ao teatro, como as obras de Henrique Marinho (1904), Mucio da Paixão (1936) ou Lafayette Silva (1938), incluíram a abordagem de outras atividades, como formação de companhias, presença de atores etc. Porém, embora tragam informações relevantes, não se pautavam pelo rigor que se exige atualmente do relato histórico, com citações de fontes, autores,

1 Lembremos que no Brasil o Arquivo Público do Império data de 1838.

2 Cf. Faria (2010). 
confrontações de versões e outras práticas. Isso impede que confirmemos as informações e confiemos nas análises oferecidas. Hoje, o controle na pesquisa e na apresentação de dados e documentos usados para elaborar os estudos do teatro brasileiro seguem as mesmas práticas estritas de outras investigações de caráter histórico ${ }^{3}$.

Nos últimos tempos, o estudo da história do teatro brasileiro e os tradicionais trabalhos sobre a literatura dramática que se mantêm enveredam para diversificados aspectos da encenação, da inserção do teatro no ambiente urbano, da arquitetura teatral, dos negócios da cena, dos profissionais do palco e de outros inúmeros aspectos até hoje menos explorados. Para esses novos objetos, novos documentos precisaram ser encontrados em instituições além de bibliotecas, em formatos os mais diversos, de acordo com o perfil de cada pesquisa.

A existência, preservação e disponibilização de conjuntos documentais que podem ser úteis aos novos questionamentos a respeito da história do teatro no Brasil não se dão de maneira natural ${ }^{4}$ ou impositiva como os arquivos públicos e institucionais, obrigados pela legislação a serem mantidos e estarem abertos à consulta. As exceções dizem respeito apenas aos conjuntos documentais de órgãos de Estado que se dedicaram à promoção da arte teatral, seja, por exemplo, construindo e mantendo os teatros municipais ${ }^{5}$, oferecendo e organizando prêmios e festivais, constituindo esporádicas companhias oficiais ${ }^{6}$ ou outras poucas iniciativas que pontuaram a política imperial e republicana em relação à cena ${ }^{7}$. Destacam-se nesse quadro os

3 Devemos considerar também que a criação dos programas de pós-graduação em Artes Cênicas em diversas Universidades ao longo das últimas décadas contribuiu de forma decisiva para tal prática. Nada impede, entretanto, que se publiquem estudos realizados à margem da academia e que não se pautem pelas mesmas exigências.

4 Conjunto de documentos produzidos e acumulados por uma entidade coletiva, pública ou privada, pessoa ou família, no desempenho de suas atividades, independentemente da natureza do suporte (BRASIL, 2005).

5 Que deveriam ser encontrados nos fundos das secretarias municipais de cultura ou das câmaras de diversos municípios. Parte da documentação pode permanecer no próprio teatro. Alguns desses teatros conseguiram criar seus próprios museus (o que não é o mesmo que possuir seu próprio arquivo), como o Theatro Municipal de São Paulo ou o Teatro São Pedro, de Porto Alegre.

6 Comédia Brasileira (1940-1945); Companhia Dramática Nacional (1953-1954); Teatro Nacional de Comédia (1956-1967)

7 Apenas como lembrança: O Teatro da Exposição (1908) 
documentos de polícia, geralmente uma série bem delineada e constante nos arranjos dos fundos dos ministérios ou secretarias de justiça. A maior parte do material refere-se à censura de diversos períodos, mas há também registro de alvarás de funcionamento, licenças a companhias estrangeiras e registro da presença de tropas nas salas de espetáculo, por exemplo ${ }^{8}$.

A verdade é que a maior parte desse material se encontra dispersa por diversos fundos da administração pública, perdidos nos organogramas, sempre alterados, quando não extraviados ou destruídos pela incúria governamental, pelo tempo ou pelos elementos.

Conhecer aquilo que podemos denominar como o organograma das instâncias governamentais, com seus desdobramentos no espaço e no tempo, permite entender, em grandes linhas, quais os cargos e as funções que foram sendo estabelecidos ao longo dos séculos. Embora a legislação metropolitana que os implantou fosse, no mais das vezes, bastante vaga, confusa e contraditória, chegando mesmo a sobrepor cargos e funções e criando conflitos de atuação no cotidiano dos administradores, é possível desvendar boa parte do emaranhado. (BACELLAR, 2005, p. 44)

O mapeamento e a descrição do material sobrevivente nesses ambientes deveriam ser uma iniciativa da comunidade acadêmica.

Por outro lado, a ação governamental também está presente na preservação da documentação teatral nas fundações e nos centros de cultura, muito embora nesses casos o acervo não se tenha constituído por força de lei. A Fundação Nacional de Artes (Funarte), por exemplo, foi criada em 1975 para apoiar atividades culturais (música popular e erudita e artes plásticas) no Brasil. A seu lado, existiam também o Instituto Nacional de Folclore (INF), a Fundação Nacional de Artes Cênicas (Fundacen) e a Fundação do Cinema Brasileiro (FCB). Em março de 1990, foram todas extintas, e criou-se o Instituto Brasileiro de Arte e Cultura (Ibrac), até que, em 1994, a sigla "Funarte"

8 Mencione-se, por exemplo, o acervo do "Arquivo Miroel Silveira", que neste ano de 2017 voltou para a custódia do Arquivo Público do Estado de São Paulo, depois de anos depositado na Universidade de São Paulo (USP), que contém cerca de 6 mil peças de teatro e seus respectivos prontuários de censura realizados entre 1927 e 1972. Outro conjunto importante é o que se encontra no Arquivo Nacional, chamado Fundo Delegacia Auxiliar de Polícia (6E) - seção de censura prévia, série peças teatrais e documentos avulsos, relativo à censura das peças encenadas no Rio de Janeiro de 1917 a 1940 (BRASIL, 2017). Disponível em: <goo.gl/8tFGqK>. Acesso em: 6 nov. 2017. 
substituiu "Ibrac". A Fundacen, por sua vez, surgira em 1987 com a transformação do Instituto Nacional de Artes Cênicas (Inacen), criado em 1981 a partir da mudança de nome do Serviço Nacional de Teatro (SNT), este organizado em 1937 no governo Vargas.

O acervo do atual Centro de Documentação e Informação da Funarte (Cedoc) é composto não pela lógica que preside a acumulação natural dos arquivos, mas por uma política de acumulação que teve seu ponto mais intenso no final da década de 1980, quando promoveu uma campanha de doação de documentação de e sobre pessoas ligadas às atividades teatrais ${ }^{9}$. A constituição do acervo da Funarte é exemplar para entender a dinâmica mais comum na formação de instituições de guarda de documentação sobre o teatro no Brasil. A base desses conjuntos é oriunda de doações pessoais (seja em vida, seja por herdeiros) de artistas, críticos e pesquisadores ${ }^{10}$.

Uma dinâmica de formação de acervo distinta dessa, bastante original, senão única, pode ser encontrada no Centro Cultural São Paulo (CCSP). Em 1975, a Secretaria de Cultura criou o Departamento de Informações e Documentação Artística (Idart) que, em 1982, foi anexado ao CCSP com o nome de Divisão de Pesquisas ${ }^{11}$. Sua missão original era acompanhar o teatro contemporâneo elaborando espécies de "dossiês" de espetáculos (incluindo registro fotográfico), registrar depoimentos de artistas e realizar pesquisas temáticas. Com o tempo, o Idart recolheu acervos "históricos", como o conjunto de fotos de Fred Kleeman sobre o Teatro Brasileiro de Comédia (TBC) ${ }^{12}$. Hoje, o "teatro contemporâneo" tornou-se "histórico", mas infelizmente a instituição é hoje bem menos dinâmica, muito embora ainda seja procurada para depósito de doações, como foi o caso recente do acervo do dramaturgo Jorge Andrade.

De todo modo, vê-se que grandes instituições como a Funarte ou o CCSP dependem da vontade de herdeiros para constituir seus acervos, uma vez que nada obriga que esses documentos, mesmo os de reconhecido valor

9 Um bem elaborado guia do acervo foi publicado em 2016 pela Funarte, chamado Arquivos e coleções privados. Disponível em: <goo.gl/2Ns7kD>. Acesso em: 6 nov. 2017.

10 Deixemos aqui anotado logo de início que a Funarte possui outros conjuntos que não dizem respeito ao universo teatral.

11 Hoje seu nome é Arquivo Multimeios e abriga cerca de 900 mil documentos de várias áreas artísticas, segundo informação disponibilizada em seu site.

12 Cf. Vargas (2012). 
para o patrimônio cultural do país, sejam encaminhados aos cuidados de órgãos públicos. Da mesma maneira, instituições culturais privadas, como o Instituto Moreira Salles (IMS), que conserva a documentação do ator Paulo Autran e do crítico Décio de Almeida Prado, ficam igualmente na dependência de receber ou comprar acervos que considerem relevantes.

Uma prática que teve certo destaque tempos atrás, quando estavam disponíveis incentivos oficiais para preservar acervos culturais e artísticos, sobretudo da Petrobras, mas que tem se mostrado de manutenção problemática em tempos de falta de financiamento, é a constituição de "institutos" de artistas, como o do diretor e cenógrafo Gianni Ratto. $\mathrm{O}$ destino de tais conjuntos é uma incógnita para o futuro ${ }^{13}$.

Em um nível intermediário entre a administração pública direta e a iniciativa privada, encontram-se as coleções abrigadas nas universidades. A Universidade de São Paulo (USP) possui um dos mais ricos acervos de coleções de todo tipo de documentos, artefatos, animais e arte. Basta listar alguns de seus institutos e museus para aquilatar a dimensão dos acervos: Museu Paulista (do Ipiranga), Museu de Arqueologia e Etnografia (MAE), Museu de Arte Contemporânea (MAC), Museu Oceanográfico e Museu de Zoologia (MZUSP). Inclui-se também nessa lista o Instituto de Estudos Brasileiros (IEB), criado pelo historiador Sérgio Buarque de Holanda em $1962^{14}$.

A presença de tão relevantes conjuntos na universidade se explica pelo fato de que é ela quem mais os valoriza, tendo em vista sua importância para a pesquisa científica e que, diante da falta de instâncias públicas que garantam a conservação, procura suprir essa ausência e manter o riquíssimo material.

Diante dessa mesma realidade é que se constituiu o Centro de Documentação Teatral na Escola de Comunicações e Artes (ECA-USP), colaboração entre o Laboratório de Informação e Memória do Departamento de Artes Cênicas da ECA (LIM CAC) e o Núcleo de Pesquisa do Traje de Cena da USP. A parceria dos grupos resultou na criação de um centro de documentação único

13 Sobre a existência e classificação dos acervos de interesse para a história do teatro existentes em São Paulo, consultar Elizabeth R. Azevedo (2017). Cf. o site disponível em: $<$ goo.gl/wyh8vN>. Acesso em: 6 nov. 2017.

14 Guia do acervo disponível em: <goo.gl/KYBVUL>. Acesso em: 6 nov. 2017. 
que se dedica, exclusivamente, à preservação da documentação relativa ao teatro, sobretudo paulista, e que além de conservar seu próprio acervo, se esforça para realizar projetos de pesquisa em sua área de interesse ${ }^{15}$.

O Centro de Documentação Teatral (CDT) adotou opções teórico-metodológicas que se explicam em parte pela realidade do objeto de sua ação e em parte pela sua existência dentro do ambiente universitário. Em primeiro lugar, a definição como um centro de documentação não é gratuita - nota-se que não se trata de um centro de memória, nem de um arquivo, biblioteca ou museu. "Centro de memória" implica o princípio de se preservar uma documentação que mantenha os "valores consolidados" pela instituição ou empresa na sua "cultura organizacional", com possível comprometimento com uma determinada perspectiva, menos crítica. Já um "centro de documentação" busca coletar informações e colocá-las, todas, à disposição dos pesquisadores, promovendo a crítica e a contínua reavaliação do assunto de sua eleição.

No caso do teatro, efêmero por natureza, ele pode ser tratado de maneira adequada compondo-se os elementos de arranjo e descrição de acordo com suas necessidades específicas. O que um centro de documentação dedicado ao universo teatral conserva são vestígios daqueles momentos, únicos e irreproduzíveis, nos quais o fenômeno presencial do teatro se dá. Um filme sobre um espetáculo não substitui o espetáculo; ele é um vestígio importante e bastante informativo, mas não é o espetáculo. Se nos lembrarmos que o teatro se utiliza de diversas linguagens artísticas para compor uma peça, evidencia-se a importância de tal política institucional. Os termos "centro de documentação" implicam, justamente, essa complementaridade buscada como ideal - está aí uma das diferenças básicas entre os centros de documentação e as bibliotecas, os museus e os arquivos.

Ainda que hoje em dia essas instituições procurem ampliar seus limites, agregando documentação complementar a seus acervos, a lógica que preside o arranjo, a descrição e a disponibilização desse material permanecem atrelados às suas próprias metodologias. Tradicionalmente, a biblioteca reúne de forma artificial ${ }^{16}$ documentos organizados a partir de seus conteúdos

15 Cf. o site disponível em: <goo.gl/nZaCDz>. Acesso em: 6 nov. 2017.

16 Artificial porque, ao contrário de um arquivo que deve guardar determinados materiais, 
(assuntos) sob forma de coleções ${ }^{17}$, adquiridos (compra, doação ou permuta) e não acumulados, produzidos por diversas fontes (variadas editoras) com a possibilidade de ter diversos exemplares de cada obra, todos descritos a partir de sistemas universais e predeterminados por convenções internacionais, descritos um a um.

Em comum, bibliotecas, museus e centros de documentação têm finalidades educativas, científicas e culturais. Os primeiros podem ser temáticos; um centro de documentação, no entanto, obrigatoriamente, deve ter uma área de interesse bem definida se quiser ser eficiente em suas ações. Estabelecer claramente o que o centro deve ou não preservar permite a otimização de recursos físicos, pessoais e financeiros. No caso do CDT, por exemplo, optamos por nos ater ao teatro e não abranger as artes cênicas como um todo, o que nos obrigaria a preservar também documentação relativa à dança, ao circo e à ópera.

Um museu é outro órgão colecionador que se dedica a preservar artefatos tridimensionais e que pode ter um assunto central, mas, como a biblioteca, conserva documentos oriundos de diversas fontes, descritos um a um. Contudo, ao contrário dela, eles são itens únicos.

Por fim, o arquivo define-se por receber (não comprar ou permutar ou receber em doação) documentos "que chegam a ele por passagem natural e obrigatória" (TESSITORE, 2003, p. 6), produzidos e acumulados por uma única entidade ou indivíduo, em variados suportes, formando séries ${ }^{18}$. A função de um arquivo é administrativa, jurídica, social, além de, eventualmente, cultural e científica e seus documentos são descritos em conjunto, por série. Além disso, a totalidade dos documentos

muitas vezes por força de lei, produzidos pela própria instituição como forma de registro de suas atividades e para provar direitos, uma biblioteca não produz os livros ou qualquer outro material que oferece para consulta.

17 Coleção é um conjunto de objetos que apresentam uma relação entre si, dada, arbitrariamente, por um colecionador, curador ou outro responsável pelo conjunto.

18 "Conjunto de documentos resultantes do exercício da mesma função ou atividade, documentos estes que têm idêntico modo de produção, tramitação e resolução" (BERNARDES, 1998, p. 9). Normalmente pertencem ao mesmo tipo documental (GONÇALVES, 1998, p. 14). Por exemplo, trabalhos apresentados pelos alunos ao fim de uma disciplina para aprovação. O Prof. Dr. Clóvis Garcia, titular do maior conjunto documental existente no CDT, acumulou ao longo dos anos vários exemplares desse tipo de documento. 
espelha a trajetória da entidade ou pessoa que o [arquivo] gerou, é indivisível porque somente dentro desse conjunto cada documento adquire seu pleno significado. Por isso, tem sua organização baseada na trajetória de cada entidade ou pessoa, exigindo conhecimento da relação entre os documentos e da estrutura e funções da entidade ou pessoa. (Ibid., p. 6)

Os centros de documentação, como bibliotecas e museus, não preservam uma documentação ${ }^{19}$ em caráter natural e obrigatório, mas recebem material de sua área de interesse - tratam-se de instituições híbridas por definição, que se assemelham às demais instituições de guarda, mas não se confundem com elas. "Reúne, por compra, doação ou permuta, documentos únicos ou múltiplos de origens diversas (sob a forma de originais ou cópias)" (Ibid., p. 7). Ademais, centros de documentação têm como missão não só preservar o material a eles confiado, mas também apoiar a pesquisa atuando como um centro de referência da área.

O CDT, então, tem se esforçado para atuar também como centro de referência. Cite-se, por exemplo, o Inventário da Cena Paulistana, projeto que investiga a história dos edifícios teatrais paulistanos de meados do século XVIII até o século XXI e procura deixar disponível aos pesquisadores de diversas áreas do conhecimento (teatro, arquitetura, urbanismo, história social etc.) a documentação encontrada em arquivos e coleções públicos e particulares.

Para organizar seus acervos, centros de documentação têm preferido seguir a metodologia dos arquivos, que procuram ser a expressão das atividades de seus titulares (indivíduos ou entidades) ao longo do tempo. É fundamental que alguns princípios e práticas sejam seguidos para o bom funcionamento do centro de documentação.

A necessidade de preservar a integridade do fundo e o sistema de relações que os documentos mantêm entre si e com o todo; o respeito à proveniência; a primazia do contexto sobre o conteúdo (ou do valor probatório sobre o valor informativo), nas operações de arranjo e descrição;

19 Evidentemente, tanto museus e bibliotecas quanto centros de documentação e os próprios arquivos formam seus acervos como instituições constituídas. Tais acervos passam, como todos os demais, pelas três idades arquivísticas (corrente, intermediária e permanente). 
e a impermeabilidade do arquivo em face do seu uso secundário. (CAMARGO, 2009, p. 28)

A manutenção da relação contextual entre as atividades do titular e os documentos que as expressam deve ser a base de todo arranjo elaborado. "Para a arquivística [...] a correlação entre a atividade e o documento que a viabiliza (e que, por isso, Ihe serve de prova) é crucial e constitui o núcleo básico dos procedimentos que conferem à área caráter científico" (Ibid., 2009, p. 31).

O trabalho no CDT começa com o recebimento de conjuntos documentais e seus registros iniciais em uma base de dados construída especialmente para dar conta de toda a diversidade de documentação recebida pelo centro, desde materiais textuais até objetos de cena, do papel ao audiovisual e aos têxteis. A partir da metodologia explicitada pela professora Ana Maria Camargo em seu livro Tempo e circunstância, de 2007, escrito em parceria com Silvana Goulart, a base de dados reflete a prática de contextualizar cada um dos documento ${ }^{20} \mathrm{em}$ relação à produção, ou acumulação do titular do fundo, ligando entre si, a partir dos eventos ou atividades que Ihes deram origem, todos os tipos documentais relativos a um mesmo evento. Diga-se também que, com a construção de nossa base, a recuperação de informações pode ser feita a partir de um evento determinado, em geral um espetáculo teatral, e que a possibilidade de cruzamento de dados de diferentes conjuntos pode recuperar documentos referentes a tal evento em diversas fontes ao mesmo tempo, o que enriquece enormemente a pesquisa. Contudo, ainda que façam parte de uma área de atividade específica do titular do fundo, os materiais, com raras exceções, não são descritos em série ${ }^{21}$, mas individualmente, como faria uma biblioteca ou um museu. Além disso, entendemos que as coleções de livros dos titulares (suas bibliotecas) fazem parte, como outro qualquer documento, das atividades desenvolvidas por aquele indivíduo. Desse modo, o material bibliográfico não é tratado a partir das normas da biblioteconomia, mas da arquivística.

20 Ou uma série documental. Nossa base de dados é capaz de fazer as duas coisas. $21 \mathrm{~A}$ base de dados permite a descrição individual ou em série. 
Mencione-se também as questões relativas a determinação de uma tipologia documental "teatral" que vem sendo realizada ao longo desses anos, de acordo com as possibilidades do centro e o contato com o material nele encontrado. Um exemplo seriam os "programa-cartaz" presentes em diversos dos conjuntos documentais que possuímos. Em princípio, houve uma discussão de como identificar corretamente esse material: seria um cartaz que traz também um programa, ou um programa que apresenta um cartaz? Qual o mais importante? Um programa-cartaz ou um cartaz-programa? Afinal, a solução mais simples prevaleceu; abandonou-se uma definição forçada e arbitrária para o material e fez-se com que a base de dados fosse capaz de registrar os dois "tipos" para o mesmo documento, pois eles, efetivamente, são um programa ao mesmo tempo que são um cartaz.

Assim, a constituição do CDT como um centro de documentação dedicado ao teatro se deu diante da constatação de que, apesar da existência de instituições que abriguem conjuntos documentais dessa área, não existia até então um centro voltado exclusivamente para ele. As opções que nos guiam são as dos centros de documentação, com forte ênfase na arquivologia. $A$ tarefa tem sido árdua, mas a situação da preservação documental teatral demanda um esforço grande e urgente para que não se perca mais do que já foi perdido (pensemos na documentação do século XIX e início do XX, o que resta dela?). O CDT tem buscado criar na universidade a consciência da tarefa que nos é destinada e se pautar pelas boas práticas teórico-metodológicas com a certeza de que o trabalho valerá a pena.

\section{Referências bibliográficas}

AZEVEDO. E. R. Acervos teatrais paulistanos: presente e futuro em jogo. Revista do

Arquivo Público do Estado de São Paulo, São Paulo, n. 4, p. 1-36, mar. 2017.

BACELLAR, C. Uso e mau uso dos arquivos. In: PINSKY, C. B. Fontes históricas. São Paulo: Contexto, 2005. p. 23-80.

BERNARDES, I. P. Como avaliar documentos de arquivo. São Paulo: Arquivo do Estado, 1998.

BRASIL. Ministério da Justiça. Fundo Delegacia Auxiliar de Polícia (6E): seção censura prévia; séries peças teatrais e documentos avulsos. Rio de Janeiro: MJ, 2017. Disponível em: <goo.gl/8tFGqK>. Acesso em: 6 nov. 2017. 
Presidência da República. Dicionário brasileiro de terminologia arquivística. Rio de Janeiro: Arquivo Nacional, 2005. 231 p.

CAMARGO, A. M. A. Arquivos pessoais são arquivos. Revista do Arquivo Público Mineiro, Belo Horizonte, v. 45, n. 2, p. 26-39, jul./dez. 2009.

CAMARGO, A. M. A.; GARCIA, S. Tempo e circunstância. São Paulo: IFHC, 2007.

FARIA, J. R. O lugar da dramaturgia nas histórias da literatura brasileira. Revista Sala Preta, v. 10, p. 9-25, 2010.

FUNDAÇÃO NACIONAL DE ARTES. Arquivos e coleções privados Cedoc/Funarte: guia geral. Rio de Janeiro: Funarte, 2016. Disponível em: <goo.gl/2Ns7kD>. Acesso em: 14 nov. 2017.

GONÇALVES, J. Como classificar e ordenar documentos de arquivo. São Paulo: Arquivo do Estado, 1998. 37 p. (Projeto Como Fazer, v. 2).

MARINHO, H. O theatro brasileiro (alguns apontamentos para sua história). Rio de Janeiro: H. Garnier, 1904.

PAIXÃO, M. O theatro no Brasil. Rio de Janeiro: Brasília Editora, 1936.

SILVA, L. História do teatro brasileiro. Rio de Janeiro: Ministério da Educação e Saúde, 1938.

TESSITORE, V. Como organizar centros de documentação. São Paulo: Arquivo do Estado, 2003. 52 p. (Projeto Como Fazer, v. 9).

VARGAS, M. T. Uma experiência em documentação e pesquisa. In: SEMINÁRIO DE PRESERVAÇÃO DE ACERVOS TEATRAIS, 1., 2012, São Paulo. Anais... São Paulo: ECA/USP, 2012. p. 13-18. 